Marquette University

e-Publications@Marquette

Communication Faculty Research and Publications

Communication, College of

$10-1-2006$

Measuring Responses to Commercials: A
Projective-Elicitation Approach

Lawrence Soley

Marquette University, lawrence.soley@marquette.edu

Published version. Journal of Current Issues \& Research in Advertising, Vol. 28, No. 2 (Fall 2006):

55-64. DOI. Reproduced with Permission of CtC Press. All Rights Reserved. 


\title{
Measuring Responses to Commercials: A Projective-elicitation Approach
}

\author{
Lawrence Soley
}

\begin{abstract}
Photoelicitation and projective assessment are research methods derived from visual sociology and psychoanalysis respectively. This study combined the methods by having respondents view a commercial, and then showing them one of two versions of a projective drawing showing a lone or a male-accompanied woman sitting on a couch. Respondents were told that the woman in the drawing had just seen the commercial and were asked about what the woman was thinking. The results show that a paper-and-pencil attitude measure correlated moderately with the visually-primed responses, but the visually-primed responses included psychoanalytically-predicted reactions such as denial and displacement and were dependent upon the social situation depicted in the drawing.
\end{abstract}

Two research methods employing visual stimuli are photoelicitation and projective techniques (Banks 2001; Soley and Park 2004). This study combines these techniques to better understand consumers' responses to commercials, and examines the validity of using the techniques to evaluate responses to advertising.

Photoelicitaton is derived from visual sociology, whereas projective assessment originated in psychoanalysis. Photoelicitation is usually used as part of an ethnographic research project in combination with participant observation and in-depth interviews (Banks 2001). It consists of providing informants with photographs of social situations, and having subjects describe the events in the photographs.

Although ethnographic research was originally developed by anthropologists, the type of ethnographic research most often practiced by advertising, communication and marketing researchers is derived from the "Chicago school of sociology," whose practitioners included Herbert Blumer, Howard S. Becker and Erving Goffman, who are sometimes referred to as "interactionists" (Machin 2002; Fisher and Strauss 1978). Chicago school adherents contend that meanings attached to symbols are socially created and shared by individuals during interpersonal interactions (Reid and Frazer 1983; Machin 2002). When roles or social settings change, the meanings that individuals attach to symbols may also change. Because mean-

Lawrence Soley (Ph.D., Michigan State University) is the Colnik Professor of Communication at Marquette University in Milwaukee. His articles have appeared in a variety of academic, professional and consumer publications. He is also author of Censorship, Inc. (Monthly Review), Free Radio (Westview), The News Shapers (Praeger) and Radio Warfare (Praeger). (email: soley@execpc.com) ings, attitudes and therefore responses to symbols can change depending on an individual's role and social context, adherents of the Chicago school recommend using ethnographic methods such as participant observation for research rather than surveys (Reid and Frazer 1983).

The use of ethnography has increased substantially in academic and professional marketing research during the past decade (Wasserman 2003; Wellner 2002; Chung and Alagaratnam 2001). Despite its increasing popularity, ethnography suffers from many of the same shortcomings associated with focus group research, such as small samples, high cost, and the need for skillful on-the-scene researchers (Wasserman 2003).

Ethnographic researchers, including interactionists, have recently turned to photoelicitation techniques because of their advantages. The advantages include overcoming "the awkwardness that an interviewee might feel [with depth-interviews] from being put on the spot and grilled by the interviewer" (Banks 2001, p. 88); the research becomes a collaborative process between interviewee and interviewer, as is the case with participant observation (Harper 1998); it can jog the interviewee's memories with the photographs (Banks 2001); and it can be used to evaluate a variety of variables, including values, attitudes, meanings and motivations (Prosser and Schwartz 1998). Depending on the length of the photoelicitation sessions, the method can generate larger samples than generally obtained with traditional ethnographic approaches such as participant observation.

Journal of Current Issues and Research in Advertising, Volume 28, Number 2 (Fall 2006). 
An example of an interactionist photoelictation study was conducted by van der Does et al. (1992), who studied social interactions in an ethnically-mixed Dutch neighborhood inhabited by lower-class Dutch, Surinamese, Turkish and Moroccan immigrants. The photoelicitation consisted of having informants examine photographs of neighborhood scenes. Typical of the responses, a Surinamese male interpreted a photograph containing Dutch women sitting on a bench near immigrant women on another bench as evidence of segregation, whereas a younger informant interpreted the same picture as evidence of integration.

Similar visual-based research techniques are employed in anthropology, but have been variously described as the photographic test for attitude measurement, or PHOTAM (Gates 1976), and thematic apperception tests (Nazarea et al. 1998; Collier and Collier 1986). These closely-related methods consist of showing informants in other societies photographs of social events or places, and having them tell stories about what is occurring in the photographs.

Gates (1976) showed Mexican "campesinos" a series of 21 photographs showing various situations. The respondents were asked to make up a story about "who the people [in the photo] are, what they are doing, thinking or saying, and what is going to happen next." Gates (1976) systematically coded the responses, demonstrating that the coding of open-ended responses can produce acceptable levels of reliability. Nazarea et al. (1998) showed photographs of the Manupali watershed in the Philippines to indigenous people and had them discuss the environmental features and agricultural practices shown in the photos. Collier and Collier (1986) describe a similar procedure, where residents of an Indian pueblo in New Mexico were shown photographs of activities during a holiday ceremony. The responses, showed that the most elaborate ceremonial activity appearing to be the center of attention, was not considered important by the participants.

Gates (1976), Nazarea et al. (1998), and Collier and Collier (1986) describe their approaches as originating in psychoanalytic psychology, which contends that peoples' motivations are imbedded in the unconscious and are not cognitively accessible. The motivations are kept from consciousness through repressive processes such as projection, denial, sublimation, and reaction formation, which are described by Blum (1966). To discover unconscious motivations, psychoanalysts developed a series of methods - called projective techniques-to bypass these repressive processes. Projective tests include sentence completion tests, word association tasks, and thematic apperception tests.
Thematic apperception tests (TAT) consist of ambiguous drawings and photographs that are shown to subjects who then create stories about what is happening in the pictures (Crumbaugh 1991; Rabin 1981). The major themes of the stories are analyzed in order to assess the subjects' unconsciously-held motivations and attitudes. TATs have been developed to assess general personality (Murray 1943), motivation to succeed (McClelland, Atkinson, Clark, and Lowell 1953), religiosity (Cline and Richards 1965), empowerment (Gutman 1987), and even narcissism (Lichter, Rothman and Lichter 1986).

Although similar to photoelicitation, TATs are designed to evaluate the subject's internal world, rather than the external world. However, it is clear from the van der Does et al. (1992) study that photo-elicited responses can also reveal as much about subjects' internal states as they do about the social environment. Moreover, Cronin (1998) suggests that photographs are sufficiently ambiguous to solicit emotive, rather than simple descriptive, accounts from subjects. This is undoubtedly true, as the original thematic apperception test developed by Murray (1943) for personality assessment included photographs.

Although originally developed for clinical psychological assessment, projective techniques were modified for use in communication, advertising and marketing research during the 1950s, and were quite positively accepted, at least initially (see Haire 1950; Sanford 1950/51; Rogers and Beal 1958). However, quantitative researchers such as Rothwell (1955), Luck, Wales and Taylor (1961), Kerlinger (1973), and Yoell (1974) criticized projective techniques for being ineffective, unreliable and invalid.

Largely as a result of such criticism, projective techniques declined in popularity in communication, advertising, marketing and even educational research during the middle to last decades of the twentieth century (Chang 2001; Catterall and Ibbotson 2000), but have been revived in consumer research since the mid-1990s (see McGrath 1995; Belk, Ger, and Askegaard 1997; Hussey and Duncombie 1999; Zinkhan et al. 1999), despite an absence of evidence demonstrating that the methods reliably or validly assess consumer motivations. Only a few advertising-related studies (e.g., Soley and Park 2004) using projective techniques have been published during the last decade.

Despite the criticisms directed at projective techniques by quantitatively-oriented researchers, there is evidence, although modest, suggesting projective techniques can demonstrate satisfactory levels of validity. This evidence consists of construct, predictive and concurrent validity, in addition to face, content 
and logical validation, which are essentially judgmental (Smith and Albaum 2005).

Construct validation shows that instruments are interrelated with constructs with which they are theoretically related. For example, Catanzaro and Mearns (1990) found that scores on the Rotter Incomplete Sentence Blank (RISB), a semistructured projective test used for personality assessment (Rotter, Lah and Rafferty 1992), correlated .51 with responses on the Beck Depression Inventory, which was significant and in the predicted direction. Irvin (1967) compared responses of students on an incomplete sentences test assessing self-concept and need for achievement with academic scores and found that they correlated .48 and .38 , respectively, which was also in the predicted direction. Schill and Blank (1968) found that the Rozenzweig picture frustration test, a projective pictorial instrument, was related in the predicted direction to scores on the Marlowe-Crowne social desirability scale, a self-administered instrument measuring need for approval. As predicted, high scorers on the Marlowe-Crowne scale were less likely to express anger toward their environment and more likely to mitigate blame according to the Rosenzweig test than low scorers.

In the area of predictive validity, a meta-analysis of 105 research studies using the nAchievement thematic apperception test of McClelland, Atkinson, Clark and Lowell (1953) conducted by Spangler (1992) found that the projective test correlated more highly with behavioral criteria such as occupational success and income than did self-report measures. The Miner sentence completion scale (Miner 1964), a semistructured projective instrument for measuring managerial motivation, has been shown to be significantly related to job performance ratings, salaries and managerial advancement, as well as other variables (Carson and Gilliard 1993). Miner (1980) found that scores on this projective instrument were positively associated with rank, salary, research productivity and related variables among a sample of professors.

One approach to establishing convergent validity for projective instruments is to compare these instruments with positivist, paper-and-pencil tests on the assumption that that conscious and unconscious responses will correlate. For example, a sentence completion instrument measuring superior-subordinate acceptance among air force cadets correlated on average .30 with two leadership tests and -.45 with an alienation test (Burwen, Campbell and Kidd 1956), demonstrating convergent and construct validity. Cline and Richards (1965) obtained high intercorrelations between a TAT, depth interviews and a structured belief and behavior instrument measuring religiosity, with the correlations averaging .66 . Soley and Park (2004) found that a projective pictorial instrument correlated $(\mathrm{r}=.59)$ with a semantic differential scale measuring attitude-toward-the-ad.

Although these studies provide some evidence of the validity of projective techniques, they provide only limited evidence of the usefulness of the techniques for advertising research, and at the same time suggest that projective techniques probably tap conscious responses, along with unconscious responses because they correlate with cognition-tapping instruments. Moreover, the similarity in design, use, and findings of the thematic apperception test and photoelicitation method suggest that TATs probably tap consciouslyformulated thoughts, as do photoelicited responses. The purpose of this study therefore is to evaluate the usefulness of a pictorial projective technique for evaluating responses to commercials, examining its validity and reliability, ability to generate unconscious responses, and stability across different social settings depicted in pictures.

Formally stated, this study hypothesizes that pictorial projective techniques, similar in form to the TAT and photoelicitation protocols, should be useful for evaluating responses to advertisements, but that the elicited responses will tap conscious, as well as unconscious thoughts. The first hypothesis, the test of convergent validity, is:

H1: Projective instruments will correlate with paper-and-pencil scales measuring attitude-toward-the-advertisement $(r>0)$.

Because paper-and-pencil scales, such as the semantic differential scale, measure conscious responses, a correlation with these scales would suggest that projective instruments also tap conscious responses. A significant correlation would represent convergence for the use of projective techniques for studying responses to commercials.

Psychoanalytic theory suggests that projective techniques will tap repressed responses to advertisements that are not tapped by traditional, cognition-tapping measurement instruments. This leads to the following hypothesis:

H2: Projective instruments will generate responses predicted by psychoanalytic theory that are not typically tapped by traditional advertising scales.

These responses, as predicted by psychoanalytic theory, should include reactions that are not consciously articulated, such as denial, reaction formation, projection and displacement. The test of this hypothesis is done qualitatively rather than quantitatively. 
Finally, the social settings depicted in pictorial projective techniques may change the meanings that subjects attach to stimuli, as Chicago school theory contends. If the depicted social setting in a projective instrument changes, it may therefore change the thoughts induced in subjects, producing different responses than produced by a different depiction. Based on this, the following hypothesis is proposed:

H3: Changes in the social settings depicted in projective instruments will affect responses evoked by the instruments.

Hypothesis 3 is derived from the interactionist, as well as psychoanalytic, perspective.

The method used in the study consists of showing subjects a visual stimulus, in this case a commercial, and then soliciting projective responses to it by having subjects describe the thoughts of the pictorial character, who was described as just having viewed the same commercial.

\section{Method}

Design. This study employed a hybrid mixed model design containing elements of investigational and experimental designs (see Miller 1970). As in investigations, the subjects were first exposed to a uniform stimulus (i.e., a commercial). After exposure to the commercial, subjects were then exposed to one of two versions of a projective pictorial card, showing one of two conditions: a woman sitting on a couch appearing to watch television alone or a woman sitting on a couch appearing to watch television in the presence of an adult male.

Projective Pictorial Card. Based on Soley and Park's (2004) research, a projective drawing was developed showing an adult female sitting on a sofa, looking ahead, as though at a television set. This drawing, referred to as the "woman on couch" card, was sketched using a model sitting on a sofa and looking at a television. The drawing contained more detail than a line-drawing, but less detail than traditional TAT pictures, allowing the woman to be sketched with ambiguous facial expressions (see Figure 1). Above her head was a blank balloon, representing her potential or possible thoughts. This projective drawing was used to test hypotheses 1 and 2 .

A second drawing was identical, except that it showed the woman sitting next to an adult male, thus creating a different social situation. This drawing is referred to as the "couple on the couch" card. The responses to the two projective drawings, which represent different social environments, were used to test hypothesis 3 (see Figure 2).
The drawing was in color, because research indicates that TAT pictures elicit more responses when presented in color than in black-and-white. Thomson and Bachrach (1951) found that African-American and white subjects generated more responses, operationally defined as word count, to the Thompson and standard TATs when presented in color than in blackand-white. Research also showed that retarded, handicapped and control (i.e., "normal") subjects generated significantly more words and themes to colored versions than to black-and-white versions of the same TAT pictures (Lubin 1955; Lubin and Wilson 1956).

Although the traditional thematic apperception test assessing patients' "complete personalities" consists of 20 cards presented to subjects over two days (Murray 1943), most TAT-type studies assessing specific attitudes use far fewer cards, as in this study. For example, Todd, Friedman and Kariuki (1990) used responses to two versions of a single TAT card to study the growth of interpersonal power of women as they age. McGrath (1995) used a single "line drawing of a wrapped gift in combination with a text prime" (p. 378) to understand gender differences in gift giving. Weinger (1998) showed children two illustrations of houses to measure their perceptions of class differences. Mick, DeMoss and Faber (1992) used four TATtype cards with a sample of 15 respondents.

Traditional attitude-toward-the advertisement scale. Attitude-toward-the-ad was selected as the construct to use when assessing the convergent validity of the projective responses, because attitude-toward-the-ad is a "more general construct" than other affective responses, incorporating within it responses to other components of the advertisement, such as to the illustration (Mitchell and Olson 1981, p. 326). These "more general" responses are conceptually more similar to psychoanalysis' interest in the "complete personality" rather than its component parts because it represents a global reaction to a stimulus, rather than a response to a single part. In Shimp's (1981) model, attitude-toward-the-ad is even conceptualized as a significant predictor of other affective and conative responses, including attitude-toward-the-brand and purchase intention, and there is some evidence demonstrating this to be true (MacKenzie and Lutz 1989; Muehling 1987; Cox and Locander 1987; Mitchell and Olson 1981).

Although advertising researchers use other response measures to evaluate the effectiveness of advertisements, such as brand recall, sales point recall and ad recognition, these represent purely conscious memory measures.

The self-administered paper-and-pencil instrument measuring attitude-toward-the-advertisement used to 
Figure 1

\section{"Woman on the Couch" Card}

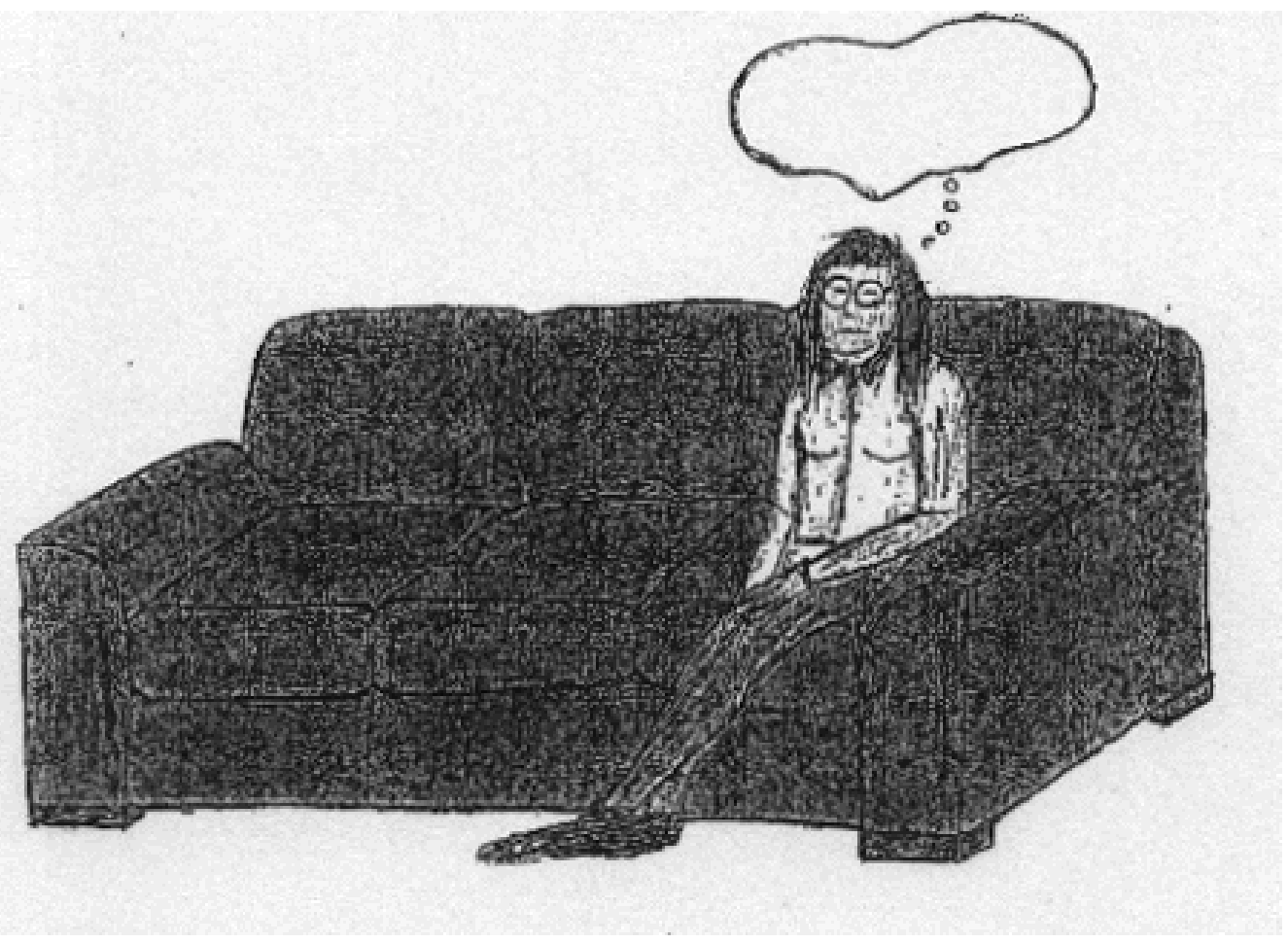

Figure 2

"Couple on the Couch" Card

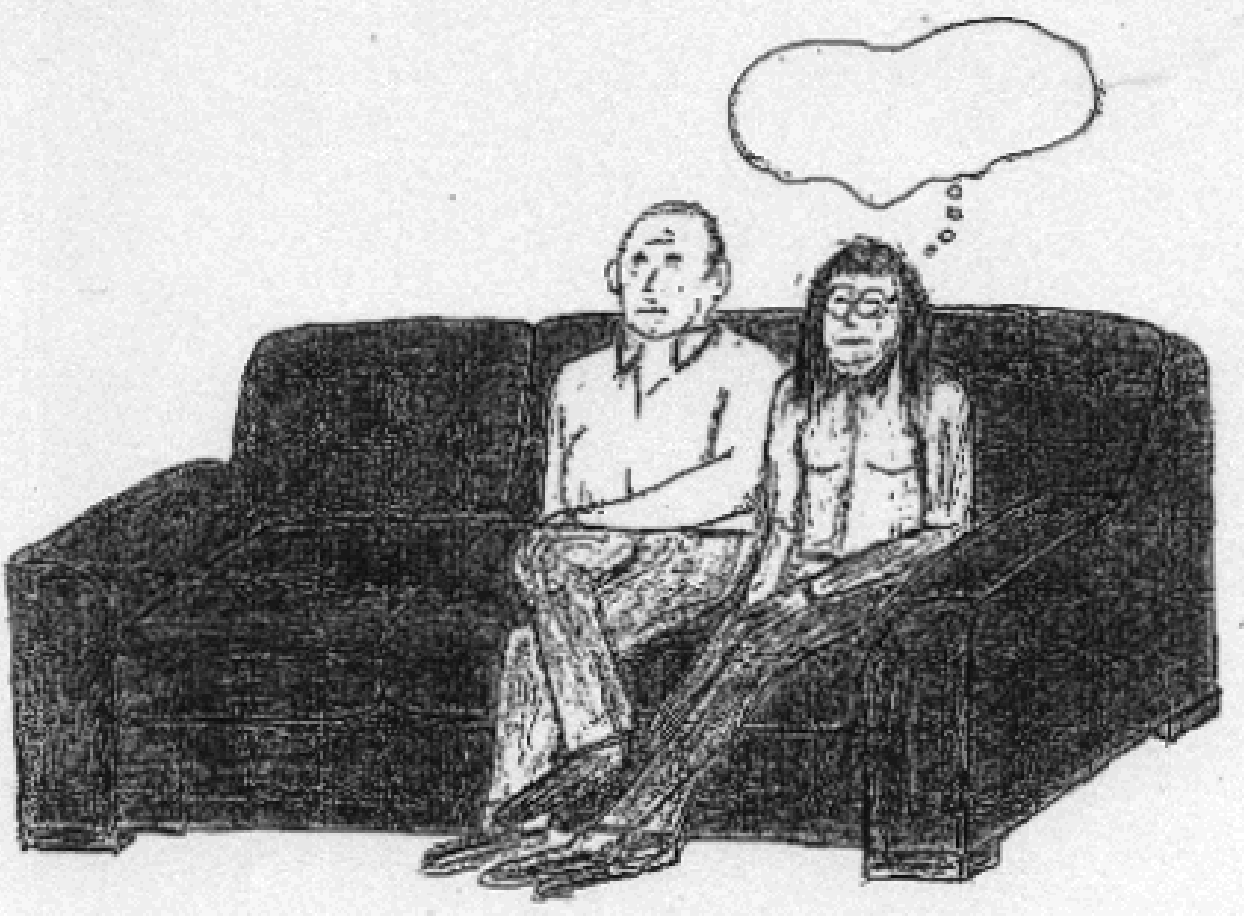


test hypotheses 1 was a set of semantic differential scales developed by Chattopadhyay and Basu (1990). The bipolar adjectives on the scale consisted of the following: pleasant-unpleasant, likeable-unlikeable, irritating-not irritating, and interesting-uninteresting. Each pair of adjectives was separated by seven scale positions.

The Chattopadhyay and Basu (1990) scale was selected because it exhibits high internal consistency (Cronbach's alpha=.91), and because its adjectives were included in the bipolar adjective list compiled by Bruner and Hensel (1996).

In addition to measuring attitude-toward-the-advertisement, the paper-and-pencil questionnaire asked respondents to provide their age using categories (e.g., 18-24 years).

For the analysis, the attitude-toward-the-ad scale items were assigned values between 1 and 7 with the negative pole (e.g., "unpleasant") receiving a value of 1 , and the most positive (e.g., "pleasant") a value of 7 .

Subjects. The subjects were 50 adult women (18+years) who were intercepted in the foyer of a government center in a suburb adjacent to a large metropolitan area. The government center houses a public library and government offices, but is less than a mile from the metropolis-suburb border, so that many metropolitan city residents visit the suburban library, which is part of a countywide system. The subjects were recruited between $10 \mathrm{a} . \mathrm{m}$. and noon on three different days.

The stimulus commercial. The commercial to which the subjects were exposed was a "sexy" beer commercials that aired on a network television sports show a year earlier. A "sexy" commercial was selected based on the Freudian assumption that it would induce more arousal and anxiety than a nonsexual commercial, an assumption for which there is empirical evidence (Ruth and Mosatche 1985). The commercial depicted bikini-clad women dancing near a fully-clothed, Caucasian "rapper." The characters appear to be college age and near a beach. Each female subject was exposed to the commercial and 5-10 seconds of video material preceding and following the commercial.

Interviewers. Two of the three interviewers were female graduate students who had completed a graduate-level research course. The third interviewer was an adult woman who already had a graduate degree. The interviewers were paid for their time, and were provided with printed instructions that were followed during the interviews.

Protocol. The interviewers intercepted every nth woman. With the printed instructions in hand, the interviewers said, "Excuse me. I was wondering whether you could spare a few minutes to participate in a university research project studying responses to television commercials." If the intercepted woman agreed to participate, she was told, "I'm going to show you a thirty-second commercial. When it's through, I'd like to ask you a few questions about it." She was then shown the commercial.

Following this, 25 subjects were shown the "woman on the couch" card as the interviewer said: "This woman is watching television. She just watched this commercial. What do you suppose she's thinking after viewing that commercial?" The participant's response was tape-recorded. The interviewer then said, "Is there anything else she's thinking?" After recording the responses, each subject was asked to complete the attitude-toward the-ad semantic differential scale.

Twenty-five subjects were also shown the "couple on the couch" card and were told: "This couple is watching television. They just watched this commercial. What do you suppose this woman is thinking after viewing that commercial?" The responses were tape recorded and afterward the interviewer then said, "Is there anything else she's thinking?" Following this response, the interviewer asked, "What do you think her husband was thinking?" These subjects also completed a paper-and-pencil semantic differential scale.

\section{Results}

Hypothesis Test 1. The projective responses to "the woman on the couch" card were transcribed from the audio-tapes, and the transcriptions were quantitatively analyzed. The quantitative analysis consisted of having two trained judges independently code the transcriptions according to whether they represented an attitude-toward-the-ad (e.g., "She thinks the commercial is sexist") statement, an attitude-toward-the-advertiser (e.g., "It seems they are using women in their underwear to sell their product") statement, or other (e.g., "The girls are way too skinny..."). This coding produced 88 percent agreement $\left(\mathrm{Scott}^{\prime} \mathrm{s} \mathrm{pi}=.71\right)$ as to whether the transcribed statements concerned attitudes toward the commercial, suggesting that coding of projective responses can produce acceptable levels of intercoder reliability.

After the initial coding, the attitude-toward-the-ad statements to the projective drawing were rated by the judges on a 5-point scale as to whether they were negative, somewhat negative, neutral or ambiguous, somewhat positive, or positive. Although there was 88 percent agreement about whether particular statements were attitude-toward-the-ad statements, the overall correlation of the two judges' ratings on the 5point scale was moderate $(\mathrm{r}=.65, \mathrm{t}=3.21, \mathrm{p}<.01)$, rather 
than strong. However, when the judges coded the statements as to whether they were negative, neutral or positive, rather than on the five-point scale, they exhibited 92 percent agreement.

Overall, the projective attitude-toward-the-advertisement responses were mostly negative. The responses to the commercial on the semantic differential scale were also negative $(\bar{x}=2.14$, s.d. $=1.35)$.

Moreover, when the average codings of the two judges for the attitude-toward-the-ad projective responses were correlated with the semantic differential attitude-toward-the-ad scale (Chattopadhyay and Basu 1990), another moderate, but significant, correlation $(\mathrm{r}=.59, \mathrm{t}=3.19, \mathrm{p}<.01)$ resulted.

When the results of the projective responses to the "couple on the couch" card, which were coded in exactly the same manner as the responses to the "woman on the couch" card, were included in the analysis, an overall correlation between the projective and semantic differential scale responses of .57 resulted, confirming hypothesis 1 . The moderate correlation shows that the projective and semantic differential measures exhibit some convergence. However, the large amount of unexplained variance (i.e., 67 percent) suggests that the projective and semantic differential responses also tap somewhat different responses.

Hypothesis Test 2. Even though the quantitativelycoded projective responses correlate significantly with responses on the attitude-toward-the-ad scale, the qualitative analysis of responses suggests that projective instruments measure different attitudes than traditional pencil-and-paper instruments, as hypothesis 2 predicts. Although respondents did provide evaluations of the commercials and a few evaluations of the brand or advertiser with statements such as "It makes me not want to buy [that brand]," more than half the responses were neither "attitude-toward-thead" nor "attitude-toward-the-brand" responses.

One set of responses to the "woman on the couch" card can be described as hostility to product users, who were perceived as "stupid men." These comments included "She thinks that summer, sun and women in bikinis sell more beer and that mostly stupid men drink beer," "It's a beer commercial so it's not geared toward an intellectual crowd," "It's geared toward jocks," and "It's really stupid... [but] it's only a beer commercial."

The "woman on the couch" card also produced a set of responses that can be described as "confusion." These responses included such statements as "Too much stimulation, too fast," "Based on her expression, I don't know that she's making any major links, so she's just saying, 'hummpf,'" "It's incomprehen- sible; I can't make out what he's saying," and "She's probably thinking, 'What the hell?'" Traditional paper-and-pencil scales would have a difficult time tapping such responses.

Another set of responses can be described as "social-situational" responses. These responses reflect the respondents' attitude-toward-the-advertisement, but also concern possible third party responses, particularly children's. The responses included, "If she has children like I do, she's probably a little offended because she knows her kids are taking it in... I can tune out but my kids are taking it all in," "I wouldn't want my kids to watch it," and "Probably that's not a good commercial to have on right now if kids are around."

Hypothesis Test 3. Social situational responses also surfaced among the responses to the "couple on the couch" card, but in this case it included an awareness of the presence of the male, and what he was thinking. One respondent said that the woman in the drawing was wondering what her husband was thinking; another responded, "Oh great! He wants me to look like that." Several also reported comments about children, such as, "She's glad that the kids aren't there to see that," "I'm glad my kids weren't there," or "I'd be horrified if I saw it with my kids." Another reported, "Some people are probably embarrassed by it."

Social-situational responses also surfaced in the women's descriptions of the male character's thoughts. One respondent said, "He's an older male thinking, 'My wife didn't like that," and another reported, "He likes the girls, but has to agree with his wife."

However, the "couple on the couch" card elicited somewhat different responses than the "woman on the couch" card. First, the "couple on the couch" card did not elicit statements exhibiting hostility to male beer drinkers. Rather, the "couple on the couch" card elicited some hostile evaluations of the characters in the commercials, something that was not elicited by the "woman on the couch" card. These responses include describing the bikini-clad models as "Just a bunch of hussies," and saying, "The guy in the ad looks like a goof," and "The male character doesn't look very smart. There's a lot of inappropriate behavior on spring break and kind of wild."

The responses are indicative of the psychoanalytic concept of "displacement," where individuals direct their hostility toward third parties rather than the real source of the hostility. Displacement suggests that if the subjects are anxious about their husbands' quiet appreciation of the commercial, they will direct their anger toward the characters in the commercial, rather than toward their husbands. This may also explain why subjects responding to the "couple on the couch" 
did not express hostility to male beer drinkers, a category that may include their husbands: They displaced their anxiety and hostility toward the characters in the commercial instead of toward male drinkers.

These responses suggest that the subjects can respond on an emotional level to characters in commercials, rather than just to the commercials. However, viewers' responses to characters are rarely evaluated in most studies of responses to advertising, but probably should be.

Another set of responses to the "couple on the couch" card fit the classic definition of psychodynamic "denial" - a refusal to accept reality. Denial is manifest by a refusal to admit the possible effects of openly sexual appeals on oneself and significant others. These denial comments included one saying that the woman in the projective drawing "wasn't paying attention." Another said, "It didn't register with her." These denial responses surfaced most commonly when women described the thoughts of the male character in the drawing. Several women reported, "He's not thinking too much," "He doesn't even see it," or "I can picture my husband sitting there thinking absolutely nothing." One said: "I have no idea. Maybe 'I'm thirsty.'” These denial responses were most likely to come from older respondents (biserial $\mathrm{r}=.48$ ). This denial response was not obtained with the "woman on the couch" card, suggesting that the presence of the male in the drawing - and the thoughts this produced-was responsible for these responses.

The majority, however, made comments about the male character enjoying the commercial, saying, "Don't I wish life was really like that," "A lot of nice women's bodies there" or "The girls are really cute and he would like to be on spring break."

Overall, the results confirm hypothesis 3 , which predicts that changes in the social settings depicted in projective drawings will affect subjects' responses to stimuli, such as commercials.

\section{Discussion}

Although it is possible to dismiss the results of this study by saying that unconscious, repressed attitudes do not exist, experimental research in cognitive neuroscience during the last dozen years clearly demonstrates the existence of unconscious memory, attitudes and behavioral effects (see Schacter and Graf 1986; Schacter 1992; Weston, Alison, and Zittel 1999; Dovidio, Kawakami, Johnson and Johnson1997; Cunningham, Preacher and Banaji 2001; Fazio, Jackson, Dunton and Williams 1995; Greenwald, McGhee and Schwartz 1998; Wilson, Lindsey and Schooler 2000).
This study suggests that unconscious responses to advertisements also exist, and that these unconscious responses need to be evaluated in order to fully understand individuals' responses to mediated communications.

Although skeptics of psychoanalysis might contend that cognitive science conceptions of the unconscious are not the same as the psychoanalytic unconscious, Freud and other psychoanalytic theorists did not distinguish between unconscious processes that were produced by physiological processes, as opposed to repression, leaving the door open to possible physiological and cognitive explanations for the psychoanalytic unconscious (Westen, Feit and Zittel 1999). Moreover, explanations in cognitive science about how the unconscious operates at least partly rest on the psychoanalytic conception of repression (Wilson, Lindsey and Schooler 2000). Jacoby, Lindsay and Toth (1992) contend that, despite attempts to distinguish the cognitive unconscious from the psychoanalytic unconscious, the two approaches are in many ways similar. For example, the rationale of using indirect tests in both approaches is the same: The tests "reveal unconscious needs, motivations and expectancies that would not be revealed by self-report measures" (p. 802). Lastly, instruments used to measure the cognitive unconscious, such as the "implicit association test"(Greenwald, McGhee and Schwartz 1998), are essentially computerized derivations of the psychoanalytic word association test, developed originally by Carl Jung (1910), that assesses the direction and quickness of responses to words representing attitude objects.

To test the validity and reliability of the pictorial projective instrument used in this study, the responses of subjects to projective drawings and semantic differential scales measuring attitude-toward-the-advertisement were compared. The results showed a moderate correlation between the responses, providing convergent validation for the use of projective techniques, but also suggesting that the two forms of instrumentation probably also measure different responses. The analysis suggests that projective techniques may tap conscious (or explicit) and unconscious (or implicit) responses, whereas traditional paper-andpencil instruments, such as semantic differentials, merely tap conscious responses. The unconscious responses tapped by the projective instrument included displacement and denial, along with hostility to product users and hostility to characters in the commercials.

However, a change in the social situations depicted within the projective drawings altered the projective responses elicited by the drawings, providing support for the interactionist contention that changes in social situations can alter responses of individuals to- 
ward attitude objects. The results suggest that when pictorial projective instruments are used to measure responses to advertisements or other mediated communications, the drawings should depict different social contexts in which the communications will be viewed. For example, if young men watch televised sports in groups, as well as alone, projective drawings should depict both social situations. If only one social situation is depicted, the responses that are elicited may not be generalizable to others. This is a possible danger of using traditional paper-and-pencil scales: They do not account for possible attitudinal changes induced by different social situations. In effect, paper-and-pencil scales produce static, uniform, conscious responses.

\section{References}

Banks, Marcus (2001), Visual Methods in Social Research, Thousand Oaks, CA: Sage.

Bartol, Kathryn M. and Craig E. Schneier (1985), "Internal and External Validity Issues with Motivation to Manage Research," Journal of Vocational Behavior, 26 (June), 299-305.

Belk, Russell W., Guliz Ger, and Soren Askegaard (1997), “Consumer Desire in Three Cultures: Results from Projective Research," Advances in Consumer Research, Vol. 24, Merrie Brucks and Deborah J. MacInnis, eds., Provo: UT: Association for Consumer Research, 24-28.

Blum, Gerald S. (1966), Psychodynamics: The Science of Unconscious Mental Forces, Belmont, CA: Wadsworth Publishing.

Brief, Arthur P., Ramon J. Aldag, and Thomas I. Chacko (1977), "The Miner Sentence Completion Scale: An Appraisal," Academy of Management Journal, 20 (December), 635-643.

Bruner II, Gordon C. and Paul J. Hensel (1996), Marketing Scales Handbook, Chicago: American Marketing Association.

Burwen, Leroy.S., Donald.T. Campbell, and Jerry Kidd (1956), "The Use of a Sentence Completion Test in Measuring Attitudes toward Superiors and Subordinates," Journal of Applied Psychology, 40 (4), 248-250.

Carson, Kenneth P. and Debora J. Gilliard (1993), "Construct Validity of the Miner Sentence Completion Scale," Journal of Occupational and Organizational Psychology, 66 (June) 171-175.

Catanzaro, Salvatore and Jack Mearns (1990), “Measuring Generalized Expectancies for Negative Mood Regulation: Initial Scale Development and Implications," Journal of Personality Assessment, 54, 546-563.

Catterall, Miriam and Patrick Ibbotson (2000), “Using Projective Techniques in Education Research," British Educational Research Journal, 26 (April), 245-256.

Chang, Jennifer (2001), “The Revival of Projective Techniques: Past, Present and Future Perspectives (Special Session)," Advances in Consumer Research, Vol. 28, Joan Meyers-Levy and Mary Gilly, eds., Provo, UT: Association for Consumer Research, 253-254.

Chattopadhyay, Amitava and Kunal Basu (1990), "Humor in Advertising: The Moderating Role of Prior Print Evaluation," Journal of Marketing Research, 27 (November), 466-476.

Chung, Ed and Stephen Alagaratnam (2001), "'Teach Ten Thousand Stars How Not to Dance': A Survey of Alternative Ontologies in Market Research," Qualitative Market Research, 4 (4), 224-234.

Cline, Victor B. and James M. Richards, Jr. (1965), "A Factor Analytic Study of Religious Belief and Behavior," Journal of Personality and Social Psychology, 1 (June), 569-578.
Collier, Jr., John and Malcolm Collier (1986), Visual Anthropology: Photography as a Research Method, Albuquerque: University of New Mexico Press.

Cox, Dena S. and William B. Locander (1987), "Product Novelty: Does It Moderate the Relationship between Ad Attitudes and Brand Attitudes?" Journal of Advertising, 16 (3), 39-44.

Cronin, Orla (1998), "Psychology and Photographic Theory," in Image-based Research: A Sourcebook for Qualitative Researchers, Jon Prosser, ed., Bristol, PA: Falmer Press, 69-83.

Crumbaugh, James C. (1990), A Primer of Projective Techniques for Psychological Assessment, San Diego: Libra Publishers.

Cunningham, William A., Kristopher J. Preacher, and Mahzarin R. Banaji (2001), "Implicit Attitude Measures: Consistency, Stability and Convergent Validity," Psychological Science, 12 (March), 163-170.

Dovidio, John F., Kerry Kawakami, Craig Johnson, Brenda Johnson, and Howard Adaiah (1997), "On the Nature of Prejudice: Automatic and Controlled Processes," Journal of Experimental and Social Psychology, 33 (September), 510-540.

Fazio, Russell H., Joni R. Jackson, Bridget C. Dunton, and Carol J. Williams (1995), "Variability in Automatic Activation as an Unobtrusive Measure of Racial Attitudes: A Bona Fide Pipeline?" Journal of Personality and Social Psychology, 69 (December), 1013-1027.

Fisher, B. M. and Anselm L. Strauss (1978), "Interactionism," in A History of Sociological Analysis, Tom Bottomore and Robert Nisbet, eds., New York: Basic Books, 457-498.

Frey, Lawrence, Shawny Anderson, and Paul G. Friedman (1998), "The Status of Instruction in Qualitative Communication Research Methods," Communication Education, 47 (July), 246-260.

Gardner, Meryl and George Siomkos (1986), "Toward a Methodology for Assessing Effects of In-store Atmospherics," in Advances in Consumer Research, vol. 13, Richard J. Lutz, ed., Provo, UT: Association for Consumer Research, 27-31.

Gates, M. (1976), "Measuring Peasant Attitudes toward Modernization: A Projective Method,"Current Anthropology, 17, 641-665.

Graf, Peter and Daniel L. Schacter (1985), "Implicit and Explicit Memory for New Associations in Normal and Amnesic Subjects," Journal of Experimental Psychology: Learning, Memory and Cognition, 11 (July), 501-518.

Greenwald, Anthony G. and Mahzarin R. Banaji (1995), "Implicit Social Cognition: Attitudes, Self-esteem, and Stereotypes," Psychological Review, 102 (January), 4 -27.

, Debbie E. McGhee, and Jordan L. Schwartz, (1998), "Measuring Individual Differences in Implicit Cognition: The Implicit Association Test," Journal of Personality and Social Psychology, 47 (June), 1464-1480.

Gutman, David (1987), Reclaimed Powers, New York: Basic Books.

Harper, Douglas (1998), "An Argument for Visual Sociology," in Image-based Research: A Sourcebook for Qualitative Researchers, Jon Prosser, ed., Bristol, PA: Falmer Press, 24-41.

Irvin, Floyd S. (1967), "Sentence Completion Responses and Scholastic Success or Failure," Journal of Counseling Psychology, 14, 269-271.

Jacoby, Larry L., D. Stephen Lindsay, and Jeffrey P. Toth (1992), "Unconscious Influences Revealed," American Psychologist, 47 (June), 802-809.

Jarvis, Matt (2000), Theoretical Approaches in Psychology, London: Routledge.

Jung, Carl G. (1910), “The Association Method," American Journal of Psychology, 21 (April), 219-269.

Kerlinger, Fred N. (1968, 1973), Foundations of Behavioral Research, New York: Holt, Rinehart and Winston.

Lichter, Robert, Stanley Rothman, and Linda Lichter (1986), The Media Elite, Bethesda, MD: Adler and Adler.

Lilienfeld, Scott O., James W. Wood, and Howard N. Garb (2000), "The Scientific Status of Projective Techniques," Psychological Science in the Public Interest, 1 (November), 25-66. 
Lubin, Nathan M. (1955), “The Effect of Color in TAT on Productions of Mentally Retarded Subjects," American Journal of Mental Deficiency, 60 (October), 366-370.

and M. O. Wilson (1956), "Picture Test Identification as a Function of 'Reality' (Color) and Similarity of Pictures to Subject," Journal of General Psychology, 54 (January), 31-38.

Luck, David J., Hugh G. Wales, and Donald A. Taylor (1961), Marketing Research, 2nd ed., Englewood Cliffs, NJ: Prentice-Hall.

Machin, David (2002), Ethnographic Research for Media Studies, London: Arnold.

MacKenzie, Scott B. and Richard J. Lutz (1989), “ An Empirical Examination of the Structural Antecedents of Attitude Toward the Ad in an Advertising Pretesting Context," Journal of Marketing, 53 (April), 48-65.

McClelland, David C., John W., Atkinson, Russell A. Clark, and Edgar L. Lowell (1953), The Achievement Motive, New York: Appleton-Century-Crofts.

, Richard Koestner, and Joel Weinberger (1989), "How Do Self-attributed and Implicit Motives Differ?" Psychological Review, 96 (October), 690-702.

McGrath, Mary A. (1995), "Gender Differences in Gift Exchanges: New Directions from Projections," Psychology and Marketing, 12 (August), 371-393.

Mick, David G., Michelle DeMoss, and Ronald J. Faber (1992), "A Projective Study of Motivations and Meanings of Self-Gifts," Journal of Retailing, 68 (Summer), $122-144$.

Miller, Gerald R. (1970). "Research Setting: Laboratory Studies," Methods of Research in Communication, Philip Emmert and William D. Brooks, eds., New York: Houghton Mifflin, 77-104.

Miner, John B. (1964), Scoring Guide for the Miner Sentence Completion Scale, Atlanta: Organizational Measurement Systems Press.

Mitchell, Andrew A. and Jerry C. Olson (1981), "Are Product Attribute Beliefs the Only Mediator of Advertising Effects on Brand Attitude?" Journal of Marketing Research, 18 (August), 318-332.

Muehling, Darrel D. (1987), "Comparative Advertising: The Influence of Attitude-toward-the-Brand on Brand Evaluation," Journal of Advertising, 16 (4), 43-49.

Murray, Henry A. (1943), The Thematic Apperception Test: Plates and Manual, Cambridge, MA: Harvard University Press.

Nazaria, Virginia, Robert Rhoades, Erla Bontayan, and Gabriela Flora (1998), "Defining Indicators Which Make Sense to Local People: Intra-cultural Variation in Perceptions of Natural Resources," Human Organization, 57 (Summer),159-220.

Perry, Campbell and Jean-Roch Laurence (1984), “Mental Processing Outside of Awareness: The Contributions of Freud and Janet," The Unconscious Reconsidered, Kenneth S. Bowers and Donald Meichenbaum, eds., New York: John Wiley and Sons, 9-48.

Prosser, Jon and Dona Schwartz (1998), "Photographs and the Sociological Research Process," in Image-based Research: A Sourcebook for Qualitative Researchers, Jon Prosser, ed., Bristol, PA: Falmer Press, 115-130.

Rabin, Albert I. (1981), Assessment with Projective Techniques: A Concise Introduction, New York: Springer Publishing.

Reid, Leonard N. and Charles F. Fraser (1979), "Studying the Child/ Television Advertising Relationship: A Symbolic Interactionist Approach," Journal of Advertising, 8 (Fall), 13-19.

Rogers, Everette M. and George M. Beal (1958), "Projective Techniques in Interviewing Farmers," Journal of Marketing, 23 (October), 177-179.

Rothwell, N.D. (1955), "Motivation research revisited," Journal of Marketing, 20 (October), 150-154.

Rotter, Julian B., Michael I. Lah and Janet E. Rafferty, (1992), Rotter Incomplete Sentences Blank, $2^{\text {nd }}$ Edition, New York: Harcourt Brace Jovanovich.
Ruth, William J. and Harriet S. Mosatche (1985), “A Projective Assessment of the Effects of Freudian Sexual Symbolism in Liquor Advertisements," Psychological Reports, 56 (February),183-188.

Sanford, Fillmore (1950/1951), "The Use of a Projective Device in Attitude Surveying," Public Opinion Quarterly, 14 (Winter), 697-709.

Schacter, Daniel L. (1992), “Understanding Implicit Memory,” American Psychologist, 47 (April), 559-569.

and Peter Graf (1986), "Preserved Learning in Amnesic Patients: Perspectives from Research on Direct Priming," Journal of Clinical and Experimental Neuropsychology, 8 (December), 727-743.

Schill, Thomas R. and John M. Black (1968), “Differences in Reaction to Frustration as a Function of Need for Approval," Psychological Reports, 21 (1), 87-88.

Smith, Scott M. and Gerald S. Albaum (2005), Fundamentals of Marketing Research, Thousand Oaks, CA: Sage.

Shimp, Terence A. (1981), "Attitude Toward the Ad as a Mediator of Consumer Brand Choice," Journal of Advertising, 10 (2), 9-15, 48.

Soley, Lawrence and Jin S. Park (2004), "Can Projective Responses Validly Measure Responses to Advertisements?" 2004 Proceeding of the American Academy of Advertising, Pat Rose, ed., N. Miami: Florida International University, 221-227.

Spangler, William D. (1992), "Validity of Questionnaire and TAT Measures of Need Achievement: Two Meta-analyses," Psychological Bulletin, 112 (July), 140-154.

Thompson, Charles E. and J. Bachrach, (1951), "The Use of Color in the Thematic Apperception Test," Journal of Projective Techniques, 15 (June), 173-184.

Todd, Judith, Ariella Friedman, and Priscilla W. Kariuki (1990), “Women Growing Stronger with Age: The Effect of Status in the United States and Kenya," Psychology of Women Quarterly, 14, 567-577.

Tullar, William L. (2001), "Russian Entrepreneurial Motive Patterns: A Validation of the Miner Sentence Completion Scale," Applied Psychology: An International Review, 50 (July), 422-435.

Wasserman, Todd (2003), "Sharpening the Focus," Brandweek, November 3, 28-31.

Weinger, Susan (1998), "Children Living in Poverty: Their Perception of Career Opportunities," Families in Society, 79 (May/ June), 320-330.

Wellner, A.S. (2002), “Watch Me Now," American Demographics, October, S1-S4.

Weston, Drew, Alison Feit, and Carolyn Zittel (1999), "Methodological Issues in Research Using Projective Methods," in Handbook of Research Methods in Clinical Psychology, 2nd ed., P.C. Kendall, J.N. Butcher and G.N. Holmbeck, eds., New York: John Wiley and Sons, 224-240.

Wilson, Timothy D., Samuel Lindsey, and Tonya Y. Schooler (2000), "A Model of Dual Attitudes," Psychological Review, 107 (January), 101-126.

Wittenbrink, Bernd, Charles M. Judd, and Bernadette Park (2001), "Spontaneous Prejudice in Context: Variability in Automatically Activated Attitudes," Journal of Personality and Social Psychology, 81 (November), 815-827.

Yoell, William A. (1974), "The Fallacy of Projective Techniques," Journal of Advertising, 3 (1), 33-36.

van der Does, Patricia, Sonja Edelaar, Imke Gooskens, Margreet Liefting, and Marije van Mierlo (1992), "Reading Images: A Study of a Dutch Neighborhood," Visual Sociology, 7 (1), 4-67.

Wannamaker, Catherine E. and Marvin Reznikoff (1989), "Effects of Aggressive and Nonaggressive Rock Songs on Projective and Structured Tests," Journal of Psychology, 123 (6), 561-570.

Zinkhan, George M., Margy Conchan, Ajay Gupta, and Gary Geissler (1999), "Motivations Underlying the Creation of Personal Web Pages: An Exploratory Study" Advances in Consumer Research, Vol. 26, Eric J. Arnould and Linda M. Scott, eds., Provo, UT: Association for Consumer Research, 69-74. 